This is the submitted version of a chapter in the forthcoming book (please cite that version):

Sholl, J. (forthcoming). 'Contextualizing Medical Norms: Georges Canguilhem's Surnaturalism,' in É. Giroux (Ed.) Naturalism in Philosophy of Health: Issues, Limits and Implications, pp. XX-XX. Springer: Dordrecht.

\title{
Contextualizing Medical Norms: Georges Canguilhem's Surnaturalism
}

Jonathan Sholl, University of Leuven

\section{Email: jonathan.sholl@hiw.kuleuven.be}

\begin{abstract}
One of the key criticisms of understanding health in terms of adaptation to one's environment is that medical judgments should be able to apply across environments. If we say that a condition is pathological 'for person $\mathrm{X}$ in environment $\mathrm{E}$ ', then we quickly run into problems of desirability and social values. However, many key concepts in biology entail an inability to separate the organism from its environment. In other words, it is precisely by referring to 'organism $\mathrm{X}$ in environment $\mathrm{E}$ ' that we can determine what is 'normal and natural'. In this chapter, I will argue that the role of this inseparability of organism and environment for understanding medical norms has been misunderstood and the implications of it for naturalistic theories of health and disease have gone largely unappreciated. To better understand this contextualist approach, I will discuss the ideas of John Ryle and Georges Canguilhem, focusing primarily on the latter. In Canguilhem's work we find some key arguments for why organismic norms need to be understood relative to environments and how this can help to clarify the concepts of health and disease. I will explore his peculiar form of naturalism that was based on the dynamism and variability of organisms, show how it can be clarified through more recent biological research, and mention some of its limitations.
\end{abstract}

Keywords: contextualism, surnaturalism, health and disease concepts, variation and variability, Georges Canguilhem

In his well-known 1977 essay, 'Health as a Theoretical Concept', Christopher Boorse criticizes various theories of health (and disease), one of which is that of approaching health via the biological concept of adaptation. He quickly sets aside the claim that 'adaptation' would here be understood in terms of 'Darwinian fitness' as this would imply the problematic 
conclusions that reproduction ensures health or that healthy traits are ones that result in large families. He then focuses on two claims, one positive and one negative, coming from this health as adaptation viewpoint. The positive claim is that health becomes a 'positive ideal of maximum enhancement of the abilities useful in each person's unique circumstances' (1977, 548), whereas the negative claim is that what is intolerable for one individual could be tolerable or even beneficial to another as conditions change. He argues that both fail to provide a naturalistic or value-free account of health.

He finds the negative claim at work in a few authors, e.g. in John Ryle's 1947 essay 'The Meaning of Normal' where Ryle argues that the concept of normality should be understood in terms of normal variability precisely because 'organism and environment are indivisible' (1947, 3). In other words, because what is normal in one environment could be pathological in another, 'normality' has no absolute meaning and thus should be better understood in terms of variations whose medical value largely depends on the environment in which they occur. Boorse finds this claim problematic since while something like myopia could be advantageous (i.e. desirable) in one environment but not another, it remains a disease in any environment because medical judgment 'mentions no particular environment' (1977, 549). Consequently, Ryle's account cannot provide the naturalist with a value-free concept of normality, but only with a practical account seemingly based on desirability. Regarding the positive claim of health as maximally enhanced abilities, Boorse argues that this would imply a problematic conclusion regarding disease. While the lack of many abilities that could help individuals adapt to particular environments might be bad, i.e. undesirable, this lack is not in itself pathological. As medicine simply does not make the claim that a condition is pathological for 'person X in environment E' (1977, 549), health as adaptation cannot work. He concludes that while the 'relativity of adaptation to environment' is the main attraction of such an approach, it is 'also what makes it unpromising for an analysis of disease' (1977, 549). By relativizing medical judgments to particular environments, we cannot arrive at the value-free account that naturalism is after.

Robert Woolfolk (1999) echoes this criticism of environmental relativity in the context of biological functions by arguing that such relativity struggles to prevent the pathologization of what is socially disvalued. In other words, if we define biological function relative to environmental conditions, e.g. in a 'propensity' account, and if we consider that conforming to social norms is fitness enhancing, then we seem led to label those traits that do not allow an individual to conform, and thus partake in fitness enhancing behavior in a given environment, 
as dysfunctional. Consequently, this 'relativistic' view seems unable to prevent diagnostic misuses such as drapetomania (Woolfolk 1999, 665).

However, it has been argued for quite some time that in order to understand organismic norms we cannot separate the organism from its environment: 'Just as there is no organism without an environment, so there is no environment without an organism' (Levins and Lewontin 1985, 99). In other words, it is precisely be referring to 'organism $\mathrm{X}$ in environment E' that biologists determine what is 'normal and natural'. More recently, the importance of this organism-environment indivisibility has been discussed in terms of understanding evolutionary dynamics, e.g. niche construction (Laland et al. 2007), as well as determining how physiological norms are a function of organismic responses to changing environmental demands, as illustrated by the properties of phenotypic plasticity or flexibility (Gilbert and Epel 2009; Piersma and van Gils 2011) and allostasis (McEwen and Wingfield 2003, 2010). If organisms and their functions cannot be fully understood without a reference to the environment in which they occur (Lewontin 2001), then a contextualist approach relating health judgments to a given environment - might have more biological support than is suggested by Boorse's (and Woolfolk's) critiques.

In this chapter, I will argue that this contextualist approach has been largely misunderstood and, as a result, the implications of it for Boorse's and other naturalistic theories have not been fully appreciated ${ }^{1}$. To explore the implications of this contextualist approach, I will first briefly return to Ryle's 1947 essay to highlight his central claims regarding normal variability. I will show how very similar insights were also at work in an often-overlooked philosopher of medicine, Georges Canguilhem ${ }^{2}$. Contra Boorse, Canguilhem's 'ecological' approach suggests that it is precisely relative to a given environment that health and disease should be determined: 'It is the relation between the environment and the living thing that determines what is normal in both' (1994, 354). After discussing some of the implications of contextualizing biological norms, I will then go further into Canguilhem's unique form of naturalism that has much in common with the aforementioned biological theories, e.g. phenotypic flexibility and allostasis, and show how it

\footnotetext{
${ }^{1}$ Many of the arguments made in this chapter echo previous critiques of naturalist theories of health and disease, e.g. van der Steen and Thung (1988), Ananth (2008), Kingma (2010), and Dussault and Gagné-Julien (2015), all of which point to the problem of understanding environmental or situation-specific aspects of medical judgments. This chapter will also extend some claims made in Sholl and De Block (2015).

${ }^{2}$ While much has been written about Canguilhem in France (e.g. Giroux 2010), he is still largely in the margins when it comes to the English-speaking 'analytic' discussions in philosophy of medicine. His ideas are mentioned by Nordenfelt (2007), Lemoine (2009), and Méthot $(2009,2013)$ in this context, but a more in-depth engagement with his ideas is still wanting.
} 
guides his views on health and disease. I will conclude by mentioning some possible limitations to Canguilhem's approach.

\section{Contextualizing Normality: Ryle and Canguilhem}

As mentioned above, the main aim of Ryle's 1947 essay is to show how the concept of normality can be understood in terms of normal variations: 'In man, as in all animals, variation is so constantly at work that no rigid pattern - whether anatomical, physiological, psychological, or immunological - is possible' $(1947,1)$. Ryle locates this variation on two levels: the individual and the species. For the individual, functional or physiological variations, e.g. in heart rate, blood pressure, body temperature, physico-chemical constitution etc., are what allow for bodily equilibrium to be maintained amidst changing demands. For the species, the variation which differentiates one individual from another is that which aids a species' adaptation to environmental changes, 'fitting' individuals to their environments and distributing functions throughout a population. In both instances, variability is necessary for survival such that 'there could be no adaptability without variability' (1947, 2). Moreover, both instances show the inseparability of organism and environment such that these changes are always with respect to environmental conditions, which in humans are thoroughly social and cultural.

What normal variation and variability, either for the individual or the species, reflect are the tasks the organism performs, 'the work required of the organism or its parts and to the medium in which they have their being' $(1947,4)$. 'Normality' is a function of the organism's relation to its environment. One example that Ryle gives to illustrate this claim is that of enlarged thyroid glands (hyperplasia) relative to different populations $(1947,4)$. In populations where iodine is low or absent from the diet, it is statistically normal to find such enlargements (also resulting in more cases of goitre), whereas in other populations where iodine is regularly consumed enlargements are statistically rare. The question, then, is when to consider an enlargement the sign of a disease and when it is simply the body's adaptive reaction to the environment. This question is posed precisely because not all instances of enlarged glands, i.e. not all deviations from the norm, result in disease. While Boorse claims that such examples simply point to a 'medical truism' such that some symptoms might be 'adaptive responses to environmental insult' $(1977,549)$, he seems to miss the point. For Ryle, what is 'normal' (in the statistical sense) depends on the environmental factors relevant for a given population, not only because variations reflect environmental conditions (e.g. lack 
of iodine causing enlarged thyroid glands), but also because some genetic variations resulting in hyperplasia may only become pathological in certain conditions. In other words, since variation is expected within any population, it is not merely the individual's deviation from population or even species-typical norms that determines whether hyperplasia is pathological, but the interaction between this variation and the environment in which it occurs. Consequently, explaining what the disease is requires a consideration of this mix of individual 'predispositions' and environmental triggers.

This would seem to make disease judgments problematically relativistic. Boorse (1977) picks on Ryle's example of a miner who is short and stocky as a result of heredity, childhood malnutrition, and stress, and who consequently is better adapted to work as a miner rather than being a policeman (Ryle 1947, 3). The question for Ryle, however, is not whether we should disqualify the judgment that something is a disease simply because it helps one's job and is therefore desirable ${ }^{3}$, but instead whether we can understand the concepts of normality and pathology without referring to individuals' 'environments, their work and upbringing, their food, and special hazards' $(1947,3)$. In order to understand adaptation we need to know the conditions and behaviors to which one is adapted. While these minors may have less robust levels of health due to their heredity and upbringing, it might also be that their current living and working conditions prevent further bodily degradations, thereby maintaining their functional levels. For other individuals with different bodily constitutions such conditions may produce various physical malfunctions. Again, the claim is not about desirability, but that in those conditions subnormal variation need not be pathological: it is not despite but because of the environment that the line will be drawn. Similarly, with the thyroid example the point is not that environmentally-induced instances of hyperplasia are not pathological, but that the line between normal and abnormal variation is better clarified when the environment is taken into consideration since in some environments an enlarged thyroid can be adaptive, whereas in others it can be pathological. Claiming that a condition is normal or abnormal thus requires that we answer: abnormal relative to what conditions? Microbiologist René Dubos (another author Boorse mentions) expresses a similar idea when he writes:

it is not possible to define health in the abstract. Its criteria differ with the environmental conditions and with the norms and history of the social group. The

\footnotetext{
${ }^{3}$ It should also be noted that Ryle never says that these bodily changes seen in miners are the result of the job, but that they are what allow one to better perform that job rather than another. As such, he is not even making the claim regarding desirability that Boorse $(1977,549)$ claims he is.
} 
criteria for health are conditioned even more by the aspirations and the values that govern individual lives. For this reason, the words health and disease are meaningful only when defined in terms of a given person functioning in a given physical and social environment $(1965,351)$.

Consequently, Boorse's focus on the 'positive' and 'negative' claims suggested by this 'health as adaptation' approach seems to misrepresent the arguments being made by Ryle and thus he misunderstands the role of environmental relativity for clarifying medical concepts.

Following a commentary on the very same essay by Ryle, another philosopher of medicine, Georges Canguilhem, arrives at a rather different result.

In dealing with human norms we acknowledge that they are determined as an organism's possibilities for action in a social situation rather than as an organism's functions envisaged as a mechanism coupled with the physical environment. The form and functions of the human body are the expression not only of conditions imposed on life by the environment but also of socially adopted modes of living in that environment (Canguilhem 1991, 269).

Canguilhem argues that we cannot understand whether a given biological mechanism has a function (let alone whether it could be said to dysfunction), especially in humans, without referring to the relevant sets of imposed and chosen environmental demands. In the remainder of this section, I would like to explore what I will call Canguilhem's 'eco-organismic' view of biological norms - determined relative to given organisms in their environments - and show how it provides some interesting arguments in favor of contextualizing medical judgments.

Canguilhem's general approach rests on a Darwinian understanding of organismic behavior in terms of what he calls 'biological normativity' $(1991,127)$, which he defines as the biological ability of an organism to establish a norm in a given environment. While much of his work focuses on the concept of 'norm' and its relation to averages and ideals, he does not give a precise definition of it ${ }^{4}$. However, norms may be best understood as the behavioral and physiological patterns or regularities occurring within a given range that organisms establish and maintain in relation to their environment. It is because organisms are not indifferent to their milieu that they will respond to 'external perturbations by making physiological adjustments with more or less success' (Méthot 2013, 118). Canguilhem goes on to add that as biological norms reflect that which helps or hinders an organism's activity,

\footnotetext{
${ }^{4}$ Le Blanc (1998), for example, provides a rather lengthy discussion of 'norms' in Canguilhem, and while he mentions the ideas developed here he never strays very far from Canguilhem's own terminology and thus does not provide much clarification.
} 
they are inherently linked to valuation, e.g. maintaining the organism's current range of physiological functioning through energy consumption and utilization. By linking the concept of 'norm' to biological processes he could be said to provide a naturalized account of valuation $^{5}$. He also calls this the 'hedonic' character of biological norms: the negative valuation of what is called disease arises from organismic responses to infections, lesions, mutations or pain through altered functioning, self-repair or self-medicating behavior (1991, 126). Human values, while clearly more complex, are seen as an extension of this biological non-indifference.

Canguilhem's concept of biological normativity seems quite relevant to contemporary issues in philosophy of biology in that it captures the same basic idea as expressed in 'phenotypic plasticity', or the organismic property to produce varying phenotypes as a function of environmental demands or triggers (Pigliucci 2001; West-Eberhard 2003). The idea that organisms are fundamentally responsive, or non-indifferent, to their conditions of life, as is demonstrated by the property of plasticity, permeates Canguilhem's philosophy. This can be seen in his discussions of how a given genotype can produce a range of 'values' in different environments $(2008,127)$ and how organisms are capable of adjusting their morphology and behavior throughout their life history in response to changing demands $(2012,48)$. It is the responsiveness of organisms that allows for new norms to be established, that allows for their normativity.

This inseparability is further developed when Canguilhem argues that organisms are not only shaped by their surroundings but also create and structure their environment according to their needs and activities: 'the environments in which the living beings find themselves are carved out by them, centered on them' $(1991,284)$. Through this 'niche construction' (Odling-Smee et al. 2003), organismic behaviors - from unicellular organisms enveloping foods and excreting waste, to plants altering soil chemistry, to human technology and culture - can also be seen as value-laden in that they express the organism's nonindifference towards its environment ${ }^{6}$. Again, it is because Canguilhem begins with such biological properties that he can then argue that organisms and environments are inseparable

\footnotetext{
${ }^{5}$ Here, his view comes quite close to what Etxeberria describes as 'vital normativity' or the claim that norms are intrinsic to organisms through the interactions among their organization, agency and their environment (see chapter 7 of the current volume). It is also quite close to Lennox's claim that health is an objective value based on 'biological value concepts' $(1995,503)$.

${ }^{6}$ Michel Morange $(2008,161)$ also mentions Canguilhem's similarity to niche construction, but goes on to lament the proximity of Canguilhem's ideas with Lamarckism. For a recent 'defence' of Lamarckian ideas see Jablonka and Lamb (2004).
} 
along naturalistic ${ }^{7}$ lines, and it is this non-indifference that suggests a biological or naturalistic account of valuation. This environmental and organismic relativity is what constitutes his 'eco-organismic' approach.

First, similar to the claims made by Ryle, Canguilhem argues that there is no absolute meaning to 'normality' because of this environmental relativity. 'A living being is normal in any given environment insofar as it is the morphological and functional solution found by life as a response to the demands of the environment' $(1991,144)$. Organismic morphology and function reflect environmental demands rather than an underlying 'fixed' species design (Boorse 1975). Canguilhem also claims that this relativity helps to distinguish anomalies (i.e. normal variations distinguishing one individual from another) from abnormalities (i.e. pathological variations). For Canguilhem, this distinction ultimately turns on whether the anomaly or variation affects the viability of the organism in its environment. For example, given the right conditions, a mutation leading to a wingless insect could be beneficial, whereas in other environments such a mutation might not survive (Canguilhem 1991, 142). This is often a problem that troubles biostatistical approaches like Boorse's since an extreme variation, such as a genetic mutation, that produces a viable phenotype may be labeled both healthy (or normal) insofar as it is viable and pathological insofar as it is a significant deviation from the species type (Sholl and De Block 2015). Canguilhem's view suggests that mutations that produce novel functions should be considered functional based on their effects on the organism, regardless of their rarity or novelty ${ }^{8}$.

With this in mind, one could see in Canguilhem an implicit 'ecological' account of function. On the one hand, his account shares with ahistorical accounts of function the idea that biological functions are hierarchically organized and contribute to the behavior of the organism as a whole: 'in the living organism all functions are interdependent and their rhythms coordinated' (Canguilhem 1991, 84). He would also agree with Boorse that to understand what a function is and the significance of a dysfunction, one must place the given function within the 'whole of functional totality' (1991, 87), a view both received from

\footnotetext{
${ }^{7}$ Élodie Giroux $(2010,20)$ describes Canguilhem's approach to biological normativity as 'anti-reductionist naturalism', a phrase borrowed from Céline Lefève. This view can also be found in Malcolm Nicolson's materialist reading of Canguilhem $(1991,356)$.

${ }^{8}$ As Wouters (2005) points out, a proper account of biological function should be able to account for so-called 'instant organisms' whose parts can have functions even if they have no selection history.
} 
Cannon's work on homeostasis and the (then) newly emerging field of cybernetics ${ }^{9}$ (Sherrington in the case of Canguilhem $(2008,72)$ and Sommerhoff for Boorse $(1976,78$ 79)). As such, Canguilhem takes up a similar stance as the ahistorical account in seeing organisms as goal-directed and functionally interconnected complex systems.

On the other hand, Canguilhem's claim that organismic normality can only be determined in relation to the environment would distance him from the tendency of ahistorical accounts, such as Boorse's, to bracket the environment in favor of species ideals or plans. For Canguilhem, the living being and its milieu cannot be considered normal in themselves since 'it is their relationship that makes them such' $(1991,143)$. This has two important consequences regarding functions. First, a biological process or system would only be considered normal, no matter how rare, if it is capable of providing a solution to the demands of a given environment $(1991,144)$. Or, in Canguilhem's terms, it would only be normal if normative, i.e. capable of finding or creating those conditions in which it is viable. Second, functions are not fixed by any underlying species-typical design, but are plastic and capable of changing: 'functional constants are habitual norms. What habit has made, habit unmakes and remakes' $(1991,169)$. Even if we take a species-level view, we are still led to the claim that functions are labile and plastic, insofar as they are dynamically related to environmental demands: 'for each function and set of functions there is a margin where the group or species capacity for adaptation comes into play' $(1991,170)$. While this 'functional plasticity' (1991, 174) is admittedly not something that can be changed at will, it would entail that Canguilhem can accommodate the claim that what has a function in one environment, could have a different function in a different environment as organisms adapt to the changed conditions. Walsh (1996) provides the example of a mouse with large ears which in a warm environment have the function of heat dissipation, whereas if transplanted to a wet environment in which the ears happen to resemble certain plants, they can be used to attract flies which the mouse eats as its primary food source. Canguilhem would likely have agreed with the claim that in

\footnotetext{
${ }^{9}$ This similarity breaks down, however, when Boorse compares organisms to a car's design that can be described in purely functional terms without reference to a designer's intentions, e.g. 'perfect working order' as conforming to a 'fixed design' $(1975,59)$. He adds that this mechanistic analogy seems 'exact' when health ideals are determined empirically with reference to a species design. This supposed exactness seems to claim either that there is no fundamental difference between mechanistic and organic functioning or that there is something 'fixed' about species design. This can also be seen when he describes disease as a breakdown of the typical, naturally selected 'physiological machinery' (1977, 550). Canguilhem, on the other hand, was very critical of importing mechanistic metaphors into biology. While he provides rather strong philosophical and historical arguments for why this is problematic (2008, ch. 4), he also provides biological ones. For example, he mentions the 'vicariousness of functions' and the 'polyvalence of organs', i.e. functions can be taken over by other organs in the vicinity of one which fails and organs can take on multiple functions (2008, 89-90). While this variability is not infinite, it is sufficient to undermine these machine metaphors. For some recent critiques of mechanistic language in biology see Dupré (2012) and Nicholson (2012).
} 
such an example the function is determined by the role the trait plays in a given environment. It is the trait's functional plasticity that allows for its adaptability.

It should be noted that one rather important difference between Canguilhem and typical accounts of function is that most rest on a statistical account of fitness: fitness is a property of populations, not of individual organisms. While survival and reproduction are important biological and physiological processes, Canguilhem's concern is with how a trait allows/hinders a given/token organism's ability to establish a stable and flexible norm in its environment: 'the normal does not have the rigidity of a fact of collective constraint but rather the flexibility of a norm which is transformed in its relation to individual conditions' (1991, 182). This seems to imply that for Canguilhem a rare mutation only found in one organism, e.g. the morphological changes involved in a goat without forelegs (West-Eberhard 2005) or the one big-eared mouse that happens to find itself in a new environment, could very well play some role in that organism's life, helping it to survive in that environment, and its failure to perform this function could then be said to be pathological in that environment.

With this last suggestion regarding a focus on individual conditions, Canguilhem takes the environmental or ecological relativity further by arguing that normality is also relative to individual organisms: 'from one individual to the next the relativity of the normal is the rule' (2008, 130). Here he takes up what Boorse calls the 'negative' claim regarding health as adaptation. Like Ryle, Canguilhem locates this individual relativity both between and within individuals. For example, in some individuals hypoglycemia poses little to no problem, whereas in others such low blood sugar levels could be fatal $(1991,171)$. Some individuals have genetic mutations such that consuming various foods, such as those with lactose, gluten, or some proteins found in legumes (e.g. lectins), can produce serious allergic reactions, whereas in others with the same mutation there can be no problem or even a possible benefit depending on their environment (1991, 282).

Moreover, this individual context implies that demands and capacities change throughout an individual's lifetime, in part because one's behaviors and environments change, and also simply because aging entails new physiological norms. He claims, for example, that myopia would simply be part of normal variation in an agrarian society, whereas it can become abnormal in more technologically-based societies $(1991,201)$. His position is thus opposed to Boorse's claim $(1977,549)$ that myopia is a disease regardless of the environment. Here the claim is not that its abnormality rests on its being undesirable, but rather on the fact that it puts the individual into a qualitatively different relation with the demands of the environment. The variation can hinder the individual's way of living in a new environment 
regardless of whether this is desired. I will further clarify what such a hindrance entails below. Similarly, an individual with hypertension could live without any difficulty in one environment (e.g. low altitude), while experiencing constrictive symptoms such as fatigue, heart palpitations, chest pains or nausea in another (e.g. high altitude). This helps to explain why for other individuals such a change in altitude might pose no problem, e.g. someone with hypotension. In these examples the individual's condition does not change, but the value of it does as a function of the environmental demands. Similar variations also come with aging. What is normal for an older individual could be considered a deficiency for a young adult (1991, 284). This does not imply that one should compare current norms with previous ones in terms of life history, such that the incapacities associated with aging would themselves become pathologized in relation to previous norms. Rather, this is simply to stress how normality changes as a function of one's life history: 'This recognition of the individual and chronological relativity of norms is not skepticism before multiplicity but tolerance of variety' (1991, 284).

This individual context implies that the individual organism provides its own norms relative to changing conditions or demands (Canguilhem 2008, 129). It is thus relative to the individual organism in its environment that the transition from normal to pathological variation becomes clearer: 'It is the individual who is the judge of this transformation because it is he who suffers from it from the very moment he feels inferior to the tasks which the new situation imposes on him' $(1991,182)$. In both Ryle and Canguilhem, then, the central question to be answered is that of the distinction between normal and pathological variation and this is clarified by focusing on an individual's way of living in its environment.

Together, these two aspects (eco-organismic relativity) constitute what could be called Canguilhem's 'contextualism', to borrow a concept from the philosopher of medicine Lawrie Reznek (1987, 168-170). Contextualism is the view that truth conditions can be applied differently depending on the context in which a proposition is used because the terms are relational, as is the case with 'disease'. In this view, we

...cannot decide whether a judgment about disease-status is true without considering the relation of the condition to the organism, and the relation of the organism to the environment. One organism's disease is another's adaptation, as is one environment's disease another's adaptation $(1987,169)$.

Since the conditions for determining the truth of a proposition are relative to an environment, the same trait could be said to have pathological effects in one environment but not in another. A contextualist approach is supported by the above claims regarding the 
responsiveness and plasticity of organisms: the very existence and viability of biological norms are inseparable from the context in which they occur (Pigliucci 2001). In other words, it is because organisms can be normative or plastic, adapting to changing demands, that normality and pathology are relative to environments and individual organisms.

There is one interesting difference between Reznek's approach and Canguilhem's. Reznek sees 'harm' or being worse off as inescapable for understanding disease, thus supporting the normativist view that disease is inherently value-laden, relating to questions of the good life $(1987,153)$. While 'harm' and value do play some role in Canguilhem's account (e.g. the '[p]athological implies pathos', (1991, 137)), I mentioned above that he actually allows for a way to naturalize value. In other words, if we accept the claim that organisms and their parts are responsive to their conditions of life, then biological norms are already an expression of value or preferences, with disease being negatively valued ${ }^{10}$ as a restriction on or reduction of the organism's ability to maintain itself amidst changing demands.

While other differences could be found, Reznek's contextualism seems to be a useful way to think about Canguilhem's eco-organismic view of normativity. The preceding discussion suggests that if biological norms have an environmentally and individually relative character and if we are in search of a way to understand health and disease along biological lines, then a naturalistic view should also incorporate this relativity. If so, then this would challenge Boorse's claim that such contextualized judgments are not helpful for medicine.

\section{Canguilhem's Surnaturalism: Towards a Biological Theory of Health and Disease}

It is within this eco-organismic view of biological norms that Canguilhem develops an interesting theory regarding health and disease. I think it can be argued that his account of biological normativity as discussed above, which is more an account of adaptability than adaptation, allows him to view these concepts as referring to biological properties of organisms in their environments. As such, he can be said to provide a biological theory of health and disease, as opposed to a conceptual analysis (Lemoine 2015). As I will show, this theory can be understood in terms of a peculiar kind of naturalism, what I will call 'surnaturalism', which is based on the dynamism and variability of biological norms. After

\footnotetext{
10 This does not necessarily mean that health and disease are a matter of what the individual thinks, since clearly one can have a problem without knowing it. Rather, it means that these phenomena are relative to the dynamic relation between individual activities and the environment. Valuation is thus more a function of physiology than representation.
} 
discussing his ideas, I will suggest some ways that they could be supported with more recent biological research.

While he does not provide one fixed definition, and despite some variation throughout his writings, the following examples can be used to capture the core of Canguilhem's position. Health, he argues, can be defined as 'a margin of tolerance for the inconstancies of the environment' $(1991,197)$. More completely, health is characterized by 'the possibility of transcending the norm, which defines the momentary normal, the possibility of tolerating infractions of the habitual norm and instituting new norms in new situations' (1991, 196f). In this view, then, there are two sides to health: (1) the capacity to tolerate variations within what is typical for a given organism and (2) being able to adapt and establish new physiological or behavioral patterns/norms (transcending old ones) to meet changing demands (2008, 132). It is this latter aspect that shows there to be an intimate relation between health and normativity. Organisms are healthy insofar as they are normative relative to environmental fluctuations $(1991,228)$. The behavior and functioning of healthy organisms thus entails the capacity for persistent or maintained adaptability. 'Health [for Canguilhem] is not defined by the doctor but by the person, according to his or her functional needs. The role of the doctor is to help the individual adapt to their unique prevailing conditions. This should be the meaning of "personalized medicine" (Horton 2009, 781). For Canguilhem, the question of what a given deviation means for an organism's flexible capacity to meet environmental demands does not involve an a priori determination, but can only be determined by the individual organism in its particular environment. Due to the individual variations mentioned above, statistical accounts will always be insufficient to determine the line between health and disease.

Conversely, disease is 'a reduction in the margin of tolerance for the environment's inconstancies' (1991, 199), involving qualitatively different and constricted pathophysiological patterns/norms (1991, 222). Following the ideas of Kurt Goldstein (1995), Canguilhem argues that an organism is diseased when it is 'obliged by its incapacity to confront the demands of new milieus' and is thereby forced 'to live exclusively in this shrunken milieu' $(2008,132)$. In relation to the two aspects mentioned with health, disease entails a qualitatively reduced capacity for tolerating variations and for adapting to changing demands: the narrowing of normativity. Disease is thus characterized by a reduction in physiological and behavioral capacities, requiring a narrowed environment in order to survive. Disease can also be understood as involving a threshold effect whereby a quantitative variation produces qualitatively new physiological or behavioral functioning. Some examples 
that Canguilhem gives are how diabetes alters not only the kidneys but also the endocrine system and the organism's overall behaviors, the effects of hypertension on various vital organs, systemic immune reactions to infections, and the behavioral effects produced by neurological damage (1991, 80-86). The pathological condition entails pathophysiological effects that are not witnessed in healthy organisms. As this transition can entail more or less of a reduction of the organism's 'innovation possibilities' $(1991,196)$, there are various degrees to which one can be diseased. To return to the example of myopia, the reason Canguilhem claims that its abnormality is relative seems based on the degree to which one is short-sided (individual variation) and the degree to which this would involve a narrower range of functioning in a given society, hindering the individual's ability to adapt to its demands. In those societies where there is no narrowing of the individual's adaptability in order to survive, myopia need not be seen as pathological.

Moreover, Canguilhem's ecological or 'holistic' approach entails that health and disease are properties of the 'whole' organism ${ }^{11}$, not its parts, since 'in the living organism all functions are interdependent and their rhythms are coordinated' $(1991,84)$. While medicine has to localize in order to provide treatment, he stresses that we should not allow this therapeutic necessity to negate the integrated and dynamic structure of organisms. Similar to the property of 'life' (Nicholson 2014), health and disease are not to be found in the separate parts or matter comprising organisms, but in their total organization relative to a given environment ${ }^{12}$. This implies, then, that it is based on variations in how biological organization allows for external perturbations to be tolerated and how a dynamic physiology involves adjusting to changing demands that health and disease are to be understood. This approach would help to account for why not every variation, be it morphological or functional, is pathological, but can become pathological when it reduces the organism's capacities to meet the demands of its milieu.

One way of conceptualizing how this view differs from the standard naturalist account whereby health is value-free 'normal' functioning could be to see it in light of Canguilhem's

\footnotetext{
${ }^{11}$ For some critiques of this view, see Giroux (2008) and Morange (2008).

${ }^{12}$ Here Canguilhem's view could be aligned with the one developed by Saborido et al. (see chapter 6 of current volume), i.e. an organizational account according to which the systemic regulation of the organism determines whether a trait is functional depending on its contribution to this self-organization. Canguilhem's eco-organismic approach is quite close to what they say about normativity and 'adaptive regulation', as is the claim that the pathological entails a narrowed range of organismic viability for a given organism in its milieu. For both theories, disease judgments can be made relative to token organisms and their environmental demands.
} 
interest in surrealism ${ }^{13}$. Similarly to how some surrealists appealed to the transgressions of dreams and the role of the imagination for opening up new possibilities for thinking about and perceiving reality, Canguilhem's view could be called surnaturalist as it challenges what we take to be 'normal and natural'. It is naturalistic in that it defines health and disease as two distinct biological norms, and is surnaturalistic by acknowledging the plasticity and variability of living beings. Biological normativity implies that biological norms are characterized not by how they conform to what they ought to be, but by how they show what organisms are capable of in different circumstances. This surnaturalism suggests that as life continually creates novelties anything can be 'normal' insofar as it is viable in its environment, and that normality is not a matter of stable essences or regularities, but is better understood in terms of 'equilibrium and adaptability' in an environment with changing demands $(1991,269)$. What is 'normal and natural' is not to conform, but to transgress the temporary norm.

Possibly the most direct expression of this view can be found when, after referring to the surrealist poet Antonin Artaud, Canguilhem describes health as 'the capacity to surpass initial capacities, a capacity to make the body do what initially seemed beyond its means' (2012, 49). To be healthy is thus to be 'more than normal' $(1991,200 ; 2008,132)$, as it involves the assurance to take risks and test one's capacities ${ }^{14}$ : to establish new norms as conditions change. This implies that being able to abuse one's health and the threat of disease are part of healthy functioning. Saying that health is being 'more than normal' is to suggest, then, that the organism maintains its functional norms by flexibly adapting to changing demands. With such a view, health is not determined relative to unknown or hypothetical future demands, but is determined based on whether the organism actually surpasses previous capabilities so as to maintain itself when 'tested' by a given set of demands. Conversely, disease is not a failure to obtain ideal functioning, but can be said to have its own norms; it is normal 'under certain conditions and in its own way' $(1994,351)$. To be diseased is not to lack a norm, but to live according to a new norm with its own constants and unique

\footnotetext{
${ }^{13}$ This is suggested by Canguilhem's evocation of surrealism when discussing the history of the concept of monstrosity $(2008,143)$, his reference to the surrealist poet and playwright Antonin Artaud in Writings on Medicine $(2012,49)$, or his reference to the work of French social theorist Roger Caillois $(2008,186)$. In The Normal and the Pathological, Canguilhem also cites a 1957 essay by François Dagognet entitled 'Surréalisme thérapeutique et formation des concepts médicaux' which was dedicated to Gaston Bachelard whose work on the imagination was quite influential for Canguilhem and whose ideas were close to those of the surrealists. Finally, Dagognet also describes Canguilhem's work as 'vitalisme surrationnel' (2007, 24), explicitly referring to the surrealist focus on how art can transgress conventions and rules.

${ }^{14} \mathrm{He}$ even suggests that the fact that organisms have redundant parts allows for risks to be taken, for variations to be tolerated (Canguilhem 1991, 200). This is the same idea captured by the concept of 'robustness', which I will explain shortly.
} 
mechanisms $(1991,188)$. Thus, disease entails a reduction in what one is capable of doing in a given environment, whereas health involves going beyond previous capacities. Anyone who has been sick or injured has surely experienced the transition from the restrictive norm of disease to the expansive norm of health as one convalesces. If there is a qualitative difference between health as being more than normal and disease as involving its own constricted norms or regularities, then this suggests that they should be understood as involving distinct biological processes or mechanisms (Nervi 2010). This would seem to provide a more biologically coherent way to contextualize health judgments.

Moreover, the organizational and physiological properties that Canguilhem appeals to could be given some further biological support. Canguilhem's claim that organisms alter their behavior and morphology to meet changing demands could be supported by the concept of allostasis, which is defined as achieving physiological viability through change (McEwen and Wingfield 2003; Schulkin 2004). This concept is meant to better account for the dynamic and anticipatory character of biological norms that can be occluded when thinking in terms of homeostasis ${ }^{15}$ : 'Homeostatic regulation is too passive a notion for the resources required to maintain long-term viability and reproductive success' (Schulkin 2011,2). The insight of this view is that the very maintenance of biological norms is achieved through flexible and anticipatory biological responses. Another way of formulating this is by arguing that the variability of bodily parameters is more fundamental for understanding health and survival than the constancy of essential functions (Sterling 2004). In this view, the values of essential functions are not 'normal' because statistically common, but common because they reflect shifting demands. Canguilhem similarly argues that biological traits are normal not because they are frequent but frequent because they are normative or viable under given conditions (1991, 160). While regulatory mechanisms were likely selected to function within a given range, the point is that it is their variability, rather than their average value, that explains how shifting demands are met. 'This is true for all states and all parameters: average values are useless. The essential need is to occupy distinctly different states and move flexibly between them' (Sterling 2004, 25; emphasis added). Conversely, it is the rigidity characteristic of pathological mechanis which prevents demands from being met.

\footnotetext{
${ }^{15}$ A quick glance into the history of the concept of homeostasis shows that it has always struggled to deal with such variability. This is witnessed in the various concepts that have been proposed to capture this phenomenon over the years from 'predictive homeostasis' and 'rheostasis' to 'homeorhesis' (Schulkin 2011, 2). For attempts to provide a naturalistic account of health in terms of homeostasis see Ananth (2008) and Dussault and GagnéJulien (2015).
} 
Similar to what is captured by the concept of allostasis, phenotypic flexibility also refers to the physiological variability that occurs within an organism's lifetime and which is 'reversible' or temporary ${ }^{16}$ (Piersma and van Gils 2011). This entails that the so-called bodily 'constants' can fluctuate depending on changing demands. Examples of flexibility can be seen in how some animals alter their organ size, body size, internal temperature, basal metabolic rates, and even their sex depending on the time and demands of the life cycle, as well as changing food conditions (Piersma and Lindström 1997; Piersma and Drent 2003). Flexibility can be seen as an 'organismic adaptation, at the level of the individual' (Piersma and Lindström 1997, p. 137) whereby morphological and physiological changes produce behavioral changes or vice versa.

Coupled with this physiological property, we can also find support for Canguilhem's claim that biological normativity, establishing norms, is achieved as organisms are capable of tolerating variations. This can be captured in the concept of biological robustness which has been generally defined as the organizational property of biological systems that allows them to maintain their functions or performance despite internal or external perturbations (Kitano 2007). As this organizational property is systemic, it can even be understood as a property pertaining to the organism as a whole (Kitano 2004). While robustness could be seen as opposed to flexibility (or plasticity in general), with the former bringing out a system's sturdiness and the latter its malleability, what is interesting is that when dealing with complex biological systems these properties seem to reinforce one another, as when 'plasticity enables organisms to robustly adapt to a changing environment' (Kitano 2004, 828). Moreover, not only does plasticity generate robustness, but plasticity is also regulated by robust systems (Bateson and Gluckman 2011, 46). Being characterized by their responsiveness to environmental conditions, organisms maintain their robustness amidst perturbations by being capable of flexible (or allostatic) responses. Together, flexibility and robustness illustrate two adaptive properties of living beings: the one physiological, the other organizational. As these properties allow the organism to adapt to changing demands they could be used to better explain the nature of health and disease. The interesting consequence would be that in order to do so, medicine would have to make use of precisely that which Boorse seems to bracket: the organism-environment relation.

\footnotetext{
${ }^{16}$ The reason Piersma and others prefer a separate term is to distinguish flexibility from other kinds of plasticity which refer to variations within a population that are irreversible, e.g. developmental plasticity or polyphenism. With the latter, plasticity reflects various pathways taken in response to early environmental triggers that are either difficult or impossible to undo.
} 
With these considerations in mind, we are better equipped to understand the contemporary relevance of Canguilhem's contextualist and surnaturalist approach to health and disease. Recall that his contextualist approach implies that health and disease are to be made relative to a given organism in its environment, while his surnaturalism suggests that 'normal' functioning is a matter of dynamism and adapting to the changing demands that an organism faces. With these properties, organisms are characterized by their 'experience, that is to say, improvisation, the utilization of occurrences' (Canguilhem 2008, 90). Consequently, it is from within Canguilhem's theoretical framework that robustness and flexibility could become relevant for medicine, potentially allowing for a new biological theory of health and disease which would help to naturalize the 'positive' aspect of Boorse's discussion of health as adaptability.

\section{Consequences and Conclusions}

I have argued in this chapter that Boorse largely misunderstands what making health and disease relative to a given environment would entail. I have suggested some ways to understand this relativity by looking deeper into Ryle's and Canguilhem's ideas. While this reframing of Canguilhem's biomedical philosophy suggests an interesting way to understand his ideas, I will conclude by discussing two limitations. The first is that of distinguishing between failures to adapt and failed adaptations, and the second deals with the difficulty of operationalizing such an approach.

Regarding the first problem, if health is relative to the organism's ability to meet the demands of its environment, then is the failure to do so pathological or simply undesirable? According to an etiological account of biological functions (e.g. Wright 1976; Wakefield 2011), one could argue that if humans have not evolved an ability to carry out some behavior in certain environments, then the inability to do this behavior need not be the sign of a dysfunction or disease. For example, while freezing and suffocating when exposed to lunar conditions might certainly be an instance in which an organism fails to meet environmental demands and is clearly undesirable, it need not be considered a disease precisely because there is no malfunction involved. The organism is simply unlucky.

Such examples appear to challenge a contextual account, but they also seem to harbor a misunderstanding about biological norms that Canguilhem's approach could clarify. As I mentioned above, Canguilhem claims that organisms are viable not because they are selected, but they are selected because they are viable under given conditions. On the other hand, 
organisms are not selected because they live in 'normal' environments, but rather an environment becomes normal because organisms are viable in it, in part because organisms can alter their environments (Canguilhem 1988, 120). Again, organism and environment are inseparable. If it is the relation between an organism and its environment that determines whether the organism is normal or not, then it actually seems biologically accurate to claim that failures to adapt or to tolerate environmental conditions are indeed pathological.

This could be understood in the following way. First, without having to appeal to past selection history it is clear that in certain environments an organism's physiology would function in a rather restricted way, e.g. the gasping for air and rapid slowing of cellular and metabolic activity that a human would experience on the moon (or under similarly extreme conditions). It is this restriction that is the variation from the organism's norms that would be experienced as pathological (and hence 'negatively valued') in that environment. This claim is trivial in that it is unlikely that anyone would object that such conditions are harmful for humans. However, Canguilhem's concern is not to clarify the class of things that are considered 'diseased' (in this sense he is not doing traditional 'conceptual analysis'), but rather to describe what disease is. As such, it is not a matter of classifying humans as having a disease characterized by their being unable to adapt to those conditions, but a matter of arguing that it is the disruption of the organism's ability to meet environmental demands that constitutes disease. Whether or not this theory is adequate to explain disease will depend on empirical findings, not philosophical counterexamples. Furthermore, such extreme examples seem to be on the far end of a continuum regarding environmental relativity, as was discussed in the above examples of someone with hypertension moving to high altitudes or someone with a genetic mutation struggling to eat certain foods. Again, no organism or environment is normal in itself, but normality describes the relation between organisms and their environment.

In some sense, then, it is intuitive to claim that if we have never evolved to tolerate certain demands, such as living on the moon, then our inability to perform them should not be considered a dysfunction. However, an ecological or contextualist view might force us to rethink these intuitions. If health and disease are properties affecting the relation between organisms and their environments, then an inability to meet the environment's 'inconstancies' can result in a pathological condition in a given environment, regardless of the rarity of that environment. The point here is not that we have a disease simply because we are incapable of meeting certain hypothetical demands, but that this incapacity becomes pathological under those conditions. 
The second problem is that of operationalizing these definitions. In other words, while Canguilhem's approach seems promising as a way to bring to the fore different biological properties to clarify health and disease, his definitions remain difficult to measure. This difficulty is particularly acute since health and disease are not biological states, but involve dynamic relations that can vary between and within organisms and even across environments. Furthermore, since health pertains to what organisms are capable of tolerating and doing as demands change, it is a property that in some sense defies analysis and objective determination. That being said, one way to operationalize this account could be to appeal to 'ecological fitness', which is the more traditional idea of fitness as how an organism 'fits' its ecological niche. This can be defined in terms of 'those traits, dispositions, and properties of organisms that tend to suit them for (and are thereby explanatory of) survival', with survival being 'not merely reproduction' (Peacock 2011, 102; emphasis added). As ecological fitness is defined as an organismic property that is not necessarily linked to reproduction and which helps to explain an organism's survival under dynamic environmental conditions, it seems like a good candidate.

Understood in this sense, then, health could be determined in terms of how various traits (from the molecular to the psychological or behavioral) contribute to the organism's maintenance of its organizational and physiological capacities, and thus its survival, in its environment ${ }^{17}$. Since an organism's survival depends on flexibly responding to environmental demands, an organism will be ecologically fit and thus healthy as long as these capacities are maintained in a given environment. While in general this suggestion is quite in line with Canguilhem's approach, what it gains in consistency it loses in being somewhat vague. More work would be needed to provide a quantitative approach to understanding health as a form of ecological fitness.

Ultimately, Canguilhem's approach provides a way to contextualize a naturalistic account of health and disease. In doing so, some of the usual problems plaguing naturalistic approaches might be mitigated. As research into niche construction, phenotypic flexibility and allostasis suggest, organisms are quite responsive to their environment and if we are going to

\footnotetext{
${ }^{17}$ A similar claim is made by Nicholson (2014, 355), following Mossio et al. (2009), regarding the maintenance of organization: 'The very existence of an organism depends on the effects of its own activity. This means that an organism's activity is intrinsically relevant to itself. Such intrinsic relevance generates a naturalized criterion for determining what norms the organism should follow. An organism (as well as its parts) must act in accordance to the particular operational norms that enable it to maintain its organization through time. If it stops following these norms, it ceases to exist. It is therefore possible to speak of what is intrinsically "good" or "bad" for an organism by evaluating its activities and actions according to the contribution they make towards the maintenance of its organization'. See the essay by Saborido et al. in the present volume for more on how this organizational view can clarify health and disease.
} 
have a more biologically accurate account of health and disease then we need to understand how this responsiveness is a function of the environment. In other words, we need a form of 'eco-organismic medicine' that is capable of clarifying in what ways ' $\mathrm{X}$ is pathological for organism $\mathrm{O}$ in environment E'. The question, then, is whether the resulting 'relativism' is really so hard to swallow.

\section{References}

Ananth, Mahesh. 2008. In Defence of an Evolutionary Concept of Health: Nature, Norms, and Human Biology. Hampshire: Ashgate Publishing.

Bateson, Patrick, and Peter Gluckman. 2011. Plasticity, Robustness, Development and Evolution. Cambridge: Cambridge University Press.

Boorse, Christopher. 1975. On the Distinction between Disease and Illness. Philosophy and Public Affairs 5.1: 49-68.

Boorse, Christopher. 1976. Wright on Functions. The Philosophical Review 85.1: 70-86.

Boorse, Christopher. 1977. Health as a Theoretical Concept. Philosophy of Science 44.4: 542573.

Canguilhem, Georges. 1988. Ideology and Rationality in the History of the Life Sciences. Trans. A. Goldhammer. Cambridge: MIT Press.

Canguilhem, Georges. 1991. The Normal and the Pathological. Trans. C.R. Fawcett and R.S. Cohen. New York: Zone Books.

Canguilhem, Georges. 1994. A Vital Rationalist: Selected Writings from Georges Canguilhem. Trans. A. Goldhammer. New York: Zone Books. 
Canguilhem, Georges. 2008. Knowledge of Life. Trans. S. Geroulanos and D. Ginsberg. New York: Fordham University Press.

Canguilhem, Georges. 2012. Writings on Medicine. Trans. S. Geroulanos and T. Meyers. New York: Fordham University Press.

Dagognet, François. 2007. Pourquoi la maladie et le réflexe dans la philosophie biomédicale de Canguilhem? In Canguilhem: Histoire des sciences et politique du vivant, ed. JeanFrançois Braunstein, 17-25. Paris: Presses Universitaires de France.

Dubos, René. 1965. Man Adapting. New Haven: Yale University Press.

Dupré, John. 2012. Processes of Life: Essays in the Philosophy of Biology. Oxford: Oxford University Press.

Dussault, Antoine C. and Gagne-Julien, Anne-Marie. 2015. Health, Homeostasis, and the Situation-specificity of Normality. Theoretical Medicine and Bioethics 36: 61-81.

Gilbert, Scott F., and David Epel. 2009. Ecological Developmental Biology: Integrating Epigenetics, Medicine, and Evolution. Sunderland: Sinauer Associates Inc.

Giroux, Élodie. 2008. N'y a-t-il de santé que de l'individu? Un point de vue épidémiologique sur les thèses de Canguilhem. In Philosophie et Médecine: En hommage à Georges Canguilhem, ed. Hee-Jin Han, 171-193. Paris: Vrin.

Giroux, Élodie. 2010. Après Canguilhem: définir la santé et la maladie. Paris: Presses Universitaires de France.

Goldstein, Kurt. 1995. The Organism. New York: Zone Books.

Horton, Richard. 2009. What is Health? The Ability to Adapt. The Lancet 373: 781.

Jablonka, Eva, and Marion J. Lamb. 2004. Evolution in Four Dimensions: Genetic, Epigenetic, Behavioral, and Symbolic Variation in the History of Life. Cambridge: MIT Press.

Kingma, Elselijn. 2010. Paracetamol, Poison, and Polio: Why Boorse's Account of Function Fails to Distinguish Health and Disease. British Journal for the Philosophy of Science 61: 241-264.

Kitano, Hiroaki. 2004. Biological Robustness. Nature: Genetics 5: 826-837.

Kitano, Hiroaki. 2007. Towards a Theory of Biological Robustness. Molecular Systems Biology 3.137: 1-7.

Laland, Kevin N., Jeremy R. Kendal, and Gillian R. Brown. 2007. The Niche Construction Perspective: Implications for evolution and human behavior. Journal of Evolutionary Psychology 5.1-4: 51-66. 
Le Blanc, Guillaume. 1998. Canguilhem et les normes. Paris: Presses Universitaires de France.

Lemoine, Maël. 2009. The Meaning of the Opposition Between the Healthy and the Pathological and its Consequences. Medicine, Health Care and Philosophy 12: 355-362.

Lemoine, Maël. 2013. Defining Disease Beyond Conceptual Analysis: An Analysis of Conceptual Analysis in Philosophy of Medicine. Theoretical Medicine and Bioethics 34: 309-325.

Lemoine, Maël. 2015. The Naturalization of the Concept of Disease. In Classification, Disease and Evidence: New Essays in the Philosophy of Medicine, eds. Philippe Huneman, Gérard Lambert, and Marc Silberstein, 19-41. Dordrecht: Springer.

Lennox, James. G. 1995. Health as an Objective Value. The Journal of Medicine and Philosophy 20: 499-511.

Levins, Richard, and Richard Lewontin. 1985. The Dialectical Biologist. Harvard: Harvard University Press.

Lewontin, Richard. 2001. The Triple Helix: Gene, Organism, and Environment. Cambridge: Harvard University Press.

McEwen, Bruce S., and John C. Wingfield. 2003. The Concept of Allostasis in Biology and Biomedicine. Hormones and Behavior 43: 2-15.

McEwen, Bruce S., and John C. Wingfield. 2010. What's in a Name? Integrating Homeostasis, Allostasis and Stress. Hormones and Behavior 57.2: 105-111.

Méthot, Pierre-Olivier. 2009. French Epistemology Overseas: Analysing the Influence of Georges Canguilhem in Québec. Humana.Mente - Journal of Philosophical Studies 9: 3959.

Méthot, Pierre-Olivier. 2013. On the Genealogy of Concepts and Experimental Practices: Rethinking Georges Canguilhem's Historical Epistemology. Studies in History and Philosophy of Science 44: 112-123.

Morange, Michel. 2008. Retour sur le normal et le pathologique. In Philosophie et Médecine: En hommage à Georges Canguilhem, ed. Hee-Jin Han, 155-169. Paris : Vrin.

Mossio, Matteo, Cristian Saborido, and Alvaro Moreno. 2009. An Organizational Account of Biological Functions. British Journal for the Philosophy of Science 60: 813-841.

Nervi, Mauro. 2010. Mechanisms, Malfunctions and Explanation in Medicine. Biology and Philosophy 25: 215-228.

Nicholson, Daniel J. 2012. The Concept of Mechanism in Biology. Studies in History and Philosophy of Biological and Biomedical Sciences 43.1: 152-163. 
Nicholson, Daniel J. 2014. The Return of the Organism as a Fundamental Explanatory Concept in Biology. Philosophy Compass 9.5: 347-359.

Nicolson, Malcolm. 1991. The Social and the Cognitive: Resources for the Sociology of Scientific Knowledge. Studies in History and Philosophy of Science 22.2: 347-369.

Nordenfelt, Lennart. 2007. The Concepts of Health and Disease Revisited. Medicine, Health Care and Philosophy 10: 5-10.

Odling-Smee, F. John., Kevin N. Laland, and Marcus W. Feldman. 2003. Niche Construction:

The Neglected Process in Evolution. Princeton: Princeton University Press.

Peacock, Kent A. 2011. The Three Faces of Ecological Fitness. Studies in History and Philosophy of Biological and Biomedical Sciences 42: 99-105.

Piersma, Theunis, and Jan Drent. 2003. Phenotypic Flexibility and the Evolution of Organismal Design. Trends in Ecology and Evolution 18.5: 228-233.

Piersma, Theunis, and Åke Lindström. 1997. Rapid Reversible Changes in Organ Size as a Component of Adaptive Behaviour. Trends in Ecology and Evolution 12.4: 134-138.

Piersma, Theunis, and Jan A. van Gils. 2011. The Flexibility Phenotype: A Body-Centred Integration of Ecology, Physiology, and Behaviour. Oxford: Oxford University Press.

Pigliucci, Massimo. 2001. Phenotypic Plasticity: Beyond Nature and Nurture. Baltimore: Johns Hopkins University Press.

Reznek, Lawrie. 1987. The Nature of Disease. London: Routledge \& Kegan Paul.

Ryle, John A. 1947. The Meaning of Normal. The Lancet 252: 1-5.

Schulkin, Jay. 2004. Allostasis, Homeostasis, and the Costs of Adaptation, ed. Jay Schulkin. Cambridge: Cambridge University Press.

Schulkin, Jay. 2011. Social Allostasis: Anticipatory Regulation of the Internal Milieu. Frontiers in Evolutionary Neuroscience 2: 1-15.

Sholl, Jonathan, and Andreas De Block. 2015. Towards a Critique of Normalization: Canguilhem and Boorse. In Medicine and Society, New Perspectives in Continental Philosophy, ed. Darian Meacham, 141-158. Springer: Dordrecht.

Sterling, Peter. 2004. Principles of Allostasis: Optimal Design, Predictive Regulation, Pathophysiology and Rational Therapeutics. In Allostasis, Homeostasis, and the Costs of Adaptation, ed. Jay Schulkin, 17-64. Cambridge: Cambridge University Press.

van der Steen, Wim J., and P.J. Thung. 1988. Faces of Medicine: A Philosophical Study. Dordrecht: Kluwer Academic Publishers. 
Wakefield, Jerome. 2011. Darwin, Functional Explanation, and the Philosophy of Psychiatry. In Maladapting Minds: Philosophy, Psychiatry, and Evolutionary Theory, eds. Peter R. Adriaens and Andreas De Block, 143-172. Oxford: Oxford University Press.

Walsh, D.M. 1996. Fitness and Function. British Journal for the Philosophy of Science 47: 553-574.

West-Eberhard, Mary Jane. 2003. Developmental Plasticity and Evolution. New York: Oxford University Press.

West-Eberhard, Mary Jane. 2005. Developmental Plasticity and the Origin of Species Differences. Proceedings of the National Academy of Sciences 102 (suppl. 1): 6543-6549. Woolfolk, Robert L. 1999. Malfunction and Mental Illness. The Monist 82.4: 658-670.

Wouters, Arno. 2005. The Function Debate in Philosophy. Acta Biotheoretica 53: 123-151.

Wright, Larry. 1976. Teleological Explanations: An Etiological Analysis of Goals and Functions. Berkeley: University of California Press. 